\title{
Correction to: From Cerebellar Apoplexy in 1849 to Cerebellar Stroke in the 2020s: Robert Dunn's Contribution
}

\author{
Mario Manto ${ }^{1,2} \cdot$ Lazaros C. Triarhou $^{3}$
}

Published online: 5 May 2021

๑) Springer Science+Business Media, LLC, part of Springer Nature 2021

\section{Correction to: The Cerebellum}

https://doi.org/10.1007/s12311-021-01240-z

The original version of this article unfortunately has an error on reference \#6.

The author of this publication is cited incorrectly as Perlman LM. The correct author citation and reference for this publication is Lorch MP.

The entry should be changed to:

Lorch MP. The third man: Robert Dunn's (1799-1877) contribution to aphasia research in mid-nineteenth-century England. J Hist Neurosci. 2016;25:188-203.

Publisher's Note Springer Nature remains neutral with regard to jurisdictional claims in published maps and institutional affiliations.

The original article can be found online at https://doi.org/10.1007/ s12311-021-01240-z.

Mario Manto

mario.manto@ulb.be

1 Unité Des Ataxies Cérébelleuses, CHU-Charleroi, Lodelinsart, Charleroi, Belgium

2 Service Des Neurosciences, University of Mons, Mons, Belgium

3 Laboratory of Theoretical and Applied Neuroscience, University of Macedonia, Thessaloniki, Greece 